\title{
Impact Analysis of Hercynian Economic Zone on Logistics Development in Jiangxi Province
}

\author{
Wan Fusong \\ Fuzhou Vocational and Technical College, Fuzhou, China, 344000 \\ 641867762@qq.com
}

Keywords: Hercynian economic zone; Logistics of Jiangxi province; Impact

\begin{abstract}
Hercynian economic zone provides a good development opportunity for Jiangxi logistics. Jiangxi has a big advantage by undertaking coastal industrial transfer and economic transformation. Product produced in Jiangxi is sold in coastal cities and even to Taiwan. International sales model creates a broad market for logistics of Jiangxi province. But hercynian economic zone construction also brought greater competition to logistics of Jiangxi province, Jiangxi logistics must attach great importance to the planning and development of logistics industry from government to enterprises, increase investment, accelerate the construction of logistics market, and make efforts to improve logistics enterprise strength to meet the challenge.
\end{abstract}

\section{Introduction}

In recent years, our country's economy develops fast, and relations across Taiwan Strait have eased. Especially after KMT in Taiwan, fundamental changes have taken place in the relations across Taiwan Strait. Both sides agreed that people across Taiwan Strait are brothers of Chinese nation. They exchange personnel, and strengthen emotional connection, and goods, trade, technology and capital exchange is increasingly close. The cross-strait economic exchanges and interaction between each other promotes cross-strait economic integration. These are very beneficial to the welfare of people on both sides and the peaceful reunification of motherland. In response to the new economic situation, State Council issued State Council Several Opinions about Support to Speed up the Construction of Channel West Bank Economic Zone in Fujian Province to better promote the development of cross-strait economy in May 2009, and from macroscopic and government level plans the strategic positioning and development goal on the west side of the channel[1], puts forward the general requirements, implementation plan and specific measures of the construction of hercynian economic zone. The deepening of hercynian economic zone economic reform and the expanding of economic scale make regional economic zone trade increasingly close, which will have significant influence on the logistics industry in Jiangxi province hercynian economic zone. It is also the key content in this paper.

\section{The History and Development of Logistics}

\section{A. The origin of logistics}

As early as in 1935, American association of sales defined logistics as: "logistics is included in the variety of economic activity in the flow process of sales of material and services from manufacturing sites to consumer sites" [2]. It should be said that logistics industry was originally formed in western countries represented by the United States, and Europe. The United States is the earliest in establishing NCPDM namely National Council of Physical Distribution Management; By the mid-1950s, economic recovery of Japan after the second world war was committed to learning from the west, and Japan sent "handling professional delegation to the United States." In the '60s, Japan introduced the concept of logistics; And the buds of logistics in China is in the 1970s. When China began the introduction of the concept of logistics from the west and enriched the theory of logistics in constant research at the same time, our country's logistics industry also gradually grows up. 


\section{B. The development of logistics industry}

At the beginning of last century to the front of World War II, logistics on the position has been regarded as the circulation of auxiliary function in the material contained in sales and service in the circulation process. Logistics was regarded as "an extension of the market". In 1922, for example, marketing expert Fred. E. Clark put in the category of logistics into day-to-day conduct of research in his book "The Principle of Marketing".

After the Second World War, economy recovered. People had further knowledge of logistics: logistics is independent of commodity market, and is embedded in commodity market. Logistics is actually the extension of commodity markets, which not only realizes and transfers value, and constantly creates more social value. In 1962, the famous American management scientist conviction P. Druker wrote "Black Continent Economy" in "Fortune" magazine. He compared logistics to "a piece of virgin land", whose logistics value and profit concept have a huge vibrations in corporate world [3]. The idea of logistics value and profit got everyone to accept.

After the 1980s, with the development of economic globalization, logistics industry also ushered in a new period of rapid development. Society realizes logistics can create more value, and enterprise can outsource logistics, which would greatly save the cost. Many logistics company set up, and the third party logistics and global logistics mode are applied; at the same time, the development of logistics industry is more deeply, and a lot of researchers and industry put forward logistics new theories, such as green logistics, lean management, logistics and logistics systematic [4], integration, and have received good effect in practice.

\section{Hercynian Economic Zone Impact Analysis on the Development of Logistics in Jiangxi Province}

\section{A. Hercynian economic zone and its economic development}

a. Hercynian economic zone

Hercynian economic zone is called channel west bank economic zone. Channel here refers to Taiwan Strait. Hercynian economic zone now includes a range of Fujian province, southern Zhejiang Quzhou, Wenzhou, Lishui, eastern Guangdong province Meizhou, Shantou, Chaozhou, Jieyang and Ganzhou in southern Jiangxi, Yingtan, Fuzhou and Shangrao. The concept was first proposed in 2004. In the second meeting of the tenth National People's Congress of Fujian province, Fujian province governor Lu Zhangong first put forward "harmonious development, comprehensive prosperity of channel west bank economic zone". That same year, channel west bank economic zone BBS was held in Beijing. In 2009, State Council executive meeting principle passed "State Council Several Opinions about Support to Speed up the Construction of Channel West Bank Economic Zone in Fujian Province", after that, "Channel West Bank Economic Zone Development Plan" obtained the approval of the state council. These policies and measures introduced greatly promoted the all-round construction of hercynian economic zone. Pattern of hercynian economic zone development planning is "one area, five axises, nine areas" [5]. Hercynian economic zone covers an area of about 27 square kilometers, and is one of the famous regional economic zones in our country.

b. Hercynian economic zone's local economy

The mainland and Taiwan Native Island are across the sea. In the tide of reform and opening up of Chinese nation, cross-strait economic exchanges are deepening. Hercynian economic zones are regional economic zones to adapt to the new situation. It takes Fujian province as the main body, and Zhejiang, Jiangxi, Guangdong are involved. Fujian, Zhejiang, Jiangxi, and Guangdong are located in subtropical area with mild climate, abundant rainfall, and abundant all kinds of resources. Fujian province has one hundred million mu forest areas, and its forest coverage rate is the first in the country; Zhejiang, and Jiangxi are in Yangtze River delta, and since ancient times, the regions are known as "land of fish and rice", fertile land, rich agricultural and aquatic products and resources. Due to abundant property, people's diligence, good natural environment condition, regional economy of hercynian economic zone has rapid development, and has been in the forefront of national economy. In 2013, according to the country's economic development data, the GDP of guangdong province in hercynian economic zone is 6.2 trillion yuan, ranking the first; Zhejiang province the 
fourth; Fujian and Jiangxi GDP as the national 11th and 19th respectively. In Figure 3.1, we can also find the economic development in hercynian economic zone around is not balanced. Coastal areas such as Zhejiang, Fujian, and Guangdong have a significantly bigger economic development size than the inland provinces of Jiangxi, and the economic gap is apparent.

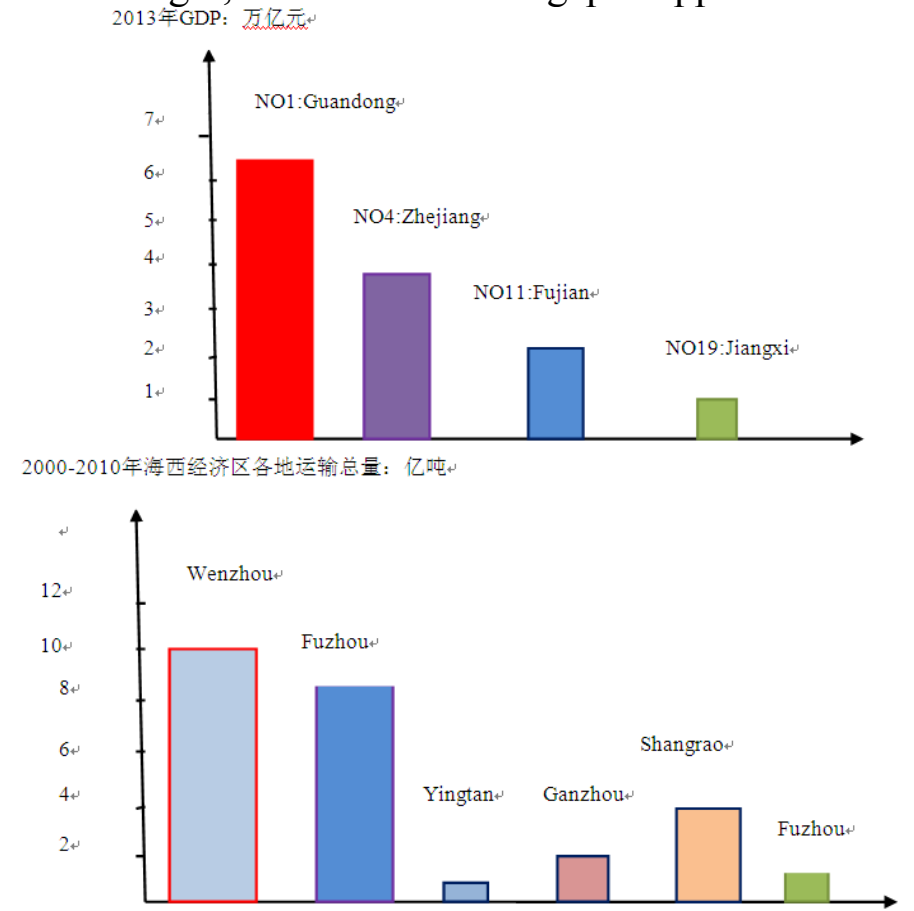

Figure 3.1 Hercynian economic zone provinces Figure 3.2 Hercynian economic zone parts of the 2013 GDP and national economy ranking 2010

\section{B. The current situation of logistics development in Jiangxi province}

Hercynian economic zone includes parts of Jiangxi province. In recent years, the logistics industry in Jiangxi province has developed rapidly. At the end of 2013, Jiangxi province has built the total mileage of 152000 kilometers, 91.1 kilometers highway density per hundred square kilometers, and 4335 miles of highway. In terms of water transport, Gan, Poyang lake are water transport main navigation channels in Jiangxi province line which links to 101 main navigable rivers such as $\mathrm{Fu}$, Xin, Rao, Xiu. The province navigation total mileage is of 5716 kilometers, including $156 \mathrm{~km}$ channel (located in Yangtze River in Jiangxi province). Jiangxi province highway passenger and cargo transport business establishments are 173000, operating 404000 cars. In 2013, Jiangxi province highway freight volume is 1.21 billion tons, freight turnover 282.9 billion ton-km [6]. The province's total civilian vessels are 3942, and net weight is 2.294 million tonnages. Waterway freight volume in Jiangxi province was 86.76 million tons and freight turnover was 19.84 billion ton-km in 2013 . At present, there are more than 800 registered logistics enterprises in Jiangxi province, and Guangchang, Xiajiang and Gaoan have become strong counties of national logistics [7], and these counties have new vehicles, large capacity, safe undertake and a timely manner. Figure 3.2 is part of the city transportation volume of hercynian economic zone, including four cities in Jiangxi province in 2000-2010. By analysis, the four cities transportation volume in Jiangxi, Yingtan, Ganzhou, Fuzhou and Shangrao has a big gap compared to economic developed cities (e.g., Wenzhou, Fuzhou), which indicates that the development of logistics industry is not good as part of hercynian economic zone's developed regions.

\section{Hercynian economic zone's impact analysis on the development of logistics in Jiangxi province}

Hercynian economic zone construction and growth have very important influence on logistics development in Jiangxi province, which mainly embodies the following aspects:

a. Hercynian economic zone internal economic activities and industrial transfer put wings for the logistics development of Jiangxi province. The essence of enterprise is to pursue profits, so 
companies generally set up factories in the place with the cheapest and the most suitable raw material, where the prices are the best and have most promising markets, so as to minimise the cost and maximize profit. In hercynian economic zone, Guangdong, Zhejiang, Fujian are coastal open provinces with economic scale, fast development speed, relative high land, personnel and raw material cost. As a result, production must be shifted to inland provinces in order to achieve coastal provinces industrial upgrading and economic transformation. And because of its unique geographical advantage, Jiangxi is an inland province, which belongs to Hercynian economic zone, so Jiangxi has a big advantage to undertake industrial transfer, the manpower, materials and the characteristics of land resources, such as low price will attract a lot of transfer out of manufacturing enterprises to set up factories in Jiangxi. This will greatly reduce manufacturing cost. And company sales market is focused on coastal open provinces in pursuit of a higher product price and market impact. Between the production base of Jiangxi province and sales market of coastal provinces, powerful logistics capability is needed for the support of the circulation of commodities.

b. Hercynian economic zone opened up a more broad market prospect for logistics of Jiangxi province. As members of hercynian economic zone, the regional policy support, system and culture are similar. Flow of raw materials, resources, and products of Jiangxi province in hercynian economic zone will be more convenient and quick, and the cost will be cheaper. Hercynian economic zone has more open port and port construction is very good also, such as Fuzhou, Meizhou's bay pivotal ports; Xiamen international shipping and aviation hub port; Fujian coastal area has direct exchanges with Taiwan's Kinmen and Matsu [8]. By using hercynian economic zone shipping and aviation port, Jiangxi logistics industry can not only radiate hercynian economic zone, and can gradually turn island of Taiwan into a new market, and at the same time send Jiangxi commodity marketing, raw materials and resources to countries around the world, which allows the logistics market in Jiangxi province to develop and there is a wide prospect of market.

c. Hercynian economic zone construction put forward higher requirements for Jiangxi logistics. Fujian province issued "On promoting the opinions of circulation modernization", which announced that we should focus on Fuzhou, Xiamen, Quanzhou coastal city construction and get three regional modern logistics centers, and speed up the construction of modern logistics distribution center. And Zhejiang, and Guangdong have very good water transport, airport, and developed logistics industry. In the current rapid development of hercynian economic zone, these all pose serious challenges to logistics of Jiangxi province. Compared with developed coastal provinces, there are big gaps of logistics industry in Jiangxi province as follows:

1. Government support is not enough. Part of Jiangxi local government didn't realize the importance of logistics for modern enterprise. The logistics is not treated as an important industry and development; support the efforts of the logistics industry is not enough. As there is no shipping port, Jiangxi province is a big airport, less understanding of international land port limitations; And departments of railways, roads and the plane of each tube, coordinate with each other is not enough, the planning and construction of provincial government unified logistics market strength is insufficient, some existing problems with logistics market management. Individual values only charge logistics market, and neglect the service with the construction of the market.

2. It lacks a large number of professional logistics personnel. On the one hand, as a result of Jiangxi economy in hercynian economic zone belongs to lower level of development, enterprise attach no enough importance to talents with lower talents treatment and lower labor, which is difficult to retain excellent logistics talent. A lot of excellent, professional logistics personnel have to move to coastal open cities such as Guangdong, Fujian, and Shanghai, Jiangxi which restricted the development of logistics industry. And more importantly, Jiangxi logistics personnel training direction and training methods have deviation. The cultivation of "unified" concept can only produce "no characteristic" logistics personnel and it is difficult to develop logistics talent which is advantageous to the development of local economy.

3. Logistics enterprises in Jiangxi province are weak. Although Jiangxi GuangChang, Xiajiang and Gaoan have become a strong county of national logistics, under the control of total logistics of Jiangxi smaller overall, Jiangxi has few national logistics brand. Jiangxi's logistics enterprises are still 
limited to local market, enterprise strength is not strong with weak ability to resist risk and open up new markets.

\section{The countermeasures and measures of logistics industry development in Jiangxi province}

Hercynian economic zone's construction and development provides a good opportunity for the development of Jiangxi logistics, but to seize the opportunity, Jiangxi logistics needs go upstream, and take measures.

a. Government should meet the spirit of coastal industrial upgrading and economic restructuring to seize the historical opportunity, attach great importance to and from the overall planning of regional logistics hub cities - logistics- logistics park construction- logistics system, and build a high level of logistics market. From system, policy, support the development of logistics industry to improve the development of logistics enterprises environmental conditions;

b. Jiangxi province has many high quality products and excellent resources, such as Nanfeng oranges, Lushan mist tea, Gannan navel oranges, kiwi fruit, and Site wine, camphor tree, renowned Jingdezhen chinese, etc. We should shift in thinking to use industrial chain management ideas to manage production, supply and sales. Use of information technology, through the transformation and integration of business processes, members of the industry build a collaborative business partnership to enhance the competitiveness of logistics enterprises and the whole supply chain. System integration and management involved in industrial chain of packaging, transportation, storage, loading and unloading, handling, distribution processing, distribution and other logistics activities are to improve the overall efficiency of logistics industry in Jiangxi province and overall competitiveness to reduce the cost of logistics enterprises.

c. Create conditions to improve infrastructure. As inland provinces, rolling hills in Jiangxi province are necessary for further increase investment. The construction of high level of highway, railway, shipping and international airport, coordinated railways, highways, shipping and so on needs various departments responsibility to set up the construction of inland port international innovation concept to make common effort for logistics development in Jiangxi province;

d. Logistics enterprises need to improve the level of modern equipment, and attach great importance to the introduction and training of talents of logistics. Jiangxi province local products and agricultural and sideline products resources are rich due to not high logistics technology level and facilities condition, which makes a lot of local products and agricultural sideline products damaged in the process of shipping, and causes great waste. Key factor of logistics technology and management level ascension is talent. The logistics industry of Jiangxi province should develop ideas, actively introduce and cultivate a high level of professional logistics talent, especially know both logistics management and production technology, also understand agricultural and sideline products, food and so on and talents of international trade rules; Jiangxi logistics personnel training needs further change train of thought. The direction of training talents and training objective requirement are more suitable for the characteristics of regional economy. There are a lot of lakes such as Jiangxi. It has the largest fresh water lake across the country, so you need to focus on developing aquaculture side warehouse management personnel in water areas; In the part of manufacturing industry developed areas, such as, Yingtan, Nanchang, then you need to develop transportation industry, circulation processing aspects of logistics personnel. Drive the development of industrial clusters, such as machinery and electronics and construction, and lay a solid foundation for logistics and producers to be more closely together.

e. There are a lot of mineral resources logistics in Jiangxi province, including copper and tungsten reserves which are the highest in the country. Jiangxi logistics enterprises need to take the initiative to join in local industrial upgrading, actively learn from advanced coastal and international logistics enterprises, especially make full use of hercynian economic zone for hercynian convenient conditions of cross-strait exchanges to exploit new markets, such as Taiwan, southeast Asia and make efforts to grow in the fierce market competition.

\section{Conclusion}

Hercynian economic zone is a setup regional economic zone by a country in order to adapt to the new situation of economic exchanges across Taiwan straits, and it provides a good development 
opportunity for Jiangxi logistics. Because of its unique geographical advantage as inland province, Jiangxi belongs to Yu Haixi economic zone, so Jiangxi undertakes huge advantage of coastal industrial transfer and economic transformation. In Jiangxi production product, in coastal cities and even to Taiwan, international sales model will create a broad market for logistics of Jiangxi province. But hercynian economic zone construction also brings greater competition to logistics of Jiangxi province. From government to enterprises, we should attach great importance to planning, development of logistics industry for Jiangxi logistics to increase investment, accelerate the construction of logistics market, and improve logistics enterprise strength to meet the rapid development impact of hercynian economic zone on logistics of Jiangxi province.

\section{References}

[1] Zhang Qian. Logistics system engineering and application [M]. Beijing: Tsinghua University Press, 2011.9.

[2] $\mathrm{Hu}$ Chunsen, Yuan Quan. Logistics and supply chain management [M]. Wuhan: Huazhong University of Science and Technology Press, 2012.06.

[3] Fu Haiqing, Lao Jian. Logistics economic geography [M]. Beijing: Beijing Normal University Press, 2011.10.

[4] Qiu Chunlong, Zhang Guilan. Hercynian economic zone logistics spatial distribution and evolution analysis [J]. Journal of Logistics Engineering and Management. 2011, 11.

[5] Wang Yuqi. Coordination countermeasures and Suggestions for the construction of hercynian economic zone of Jiangxi province [J]. Journal of Economic Enterprises. 2010, 8.

[6] Hu Busai. Hercynian economic zone industrial structure research [D]. Xiamen University. 2014 01.

[7] Leng Shulian. Development present situation, problems and countermeasures of Jiangxi province modern logistics industry [J]. Price Issue. 2012, 11.

[8] Xiong Yan, Zhou Wei. Research on manufacturing and logistics industry linkage development of Jiangxi province [J]. Business Times. 2013, 12. 